\title{
근접장 $\mathrm{MIMO}$ 전송 환경에서의 편파 적응을 이용한 신호의 개선 방법
}

\author{
황 승 현", 고 진 환
}

\section{Signal Enhancement through Polarization Adaptivity on Transmit in a Near-Field MIMO Environment}

\author{
Seunghyeon Hwang, Jinhwan Koh \\ 요 약
}

본 논문에서는 근접장 MIMO 전송 환경에서의 수신 신호의 향상을 위해 편파적응을 이용하였다. 중첩의 원리 에 기초하여 각각의 수신 안테나에 적응화 된 송신 안테나의 가중치를 정하는 것이 이 논문의 목적이다. 편파의 원리를 이용하여 수신 안테나의 개수가 송신 안테나의 개수보다 많을 때 송신신호는 특정한 수신기로 방향성을 가질 수 있다. 수치해석적 시뮬레이션을 통하여 본 연구의 우수성을 보여주었다.

Key Words : Signal Enhancement, Polarization, Near-Field MIMO, MISO

\begin{abstract}
In this paper polarization adaptivity on transmit has been used to enhance the received signals directed to a pre-selected receiver in a near-field multi-input multi-output (MIMO) environment. The objective here is to select a set of weights on the transmitting antennas adapted to individual receivers based on the principles of reciprocity. Using the polarization properties, when the number of receiving antennas is greater than the number of transmitting antennas, the transmitted signal may be directed more to a particular receiver location while simultaneously minimizing the reception signal strength at other receivers. Numerical simulations have been made to illustrate the novelty of the proposed approach.
\end{abstract}

\section{I . Introduction}

Many methods have been developed in recent years to enhance reception of signals in a multi-input multi-output (MIMO) environment ${ }^{[1-10]}$. For mobile communication, the development of a methodology that mitigates the deleterious effects of multipath fading, near-field scatterers (buildings, trees and platforms), etc., is necessary for improved reception. How to counteract multipath fading in an adaptive antenna, which can significantly improve the performance of a system, has also been discussed ${ }^{[11-15]}$. In this paper we present an alternative way of directing the signals from the transmitter to a specific receiving antenna. Spatial diversity on transmit is obtainable at a base station, if that station has multiple antennas and the signals being fed to each

\footnotetext{
※ 본 연구는 지식경제부 및 정보통신산업진흥원의 대학IT연구센터육성 지원사업의 연구결과로 수행되었음 (NIPA -2012- H0301- 123003)

- 주저자 : 방위사업청, sehwang68@gmail.com@ paper.korean.ac.kr, 정회원

○ 교신저자 : 경상대학교 전자공학과 공학연구원, jikoh@gnu.ac.kr, 정회원

논문번호 : KICS2011-11-512, 접수일자 : 2011년 11월 9일, 최종논문접수일자 : 2012년 8월 1일
} 
transmitting antenna corresponding to a particular receiver are weighted. At a mobile receiver there is generally no spatial diversity. In this way, the transmitted signals would be received at the designated receiver, when weighted appropriately while it would be canceled at the other locations. By providing spatial diversity on transmit it is possible to mitigate the effects of multipath fading, as the directed energy from the transmitted antennas, would combine vectorially at the selected receiving antenna element either to produce a maximum or a minimum. This methodology is based on the reciprocity theorem [16] and is applied to a collection of receiving and transmitting antennas. The near-field represents the dimension of the transmitter is large enough to the distance between the transmitter and receiver so that the wave cannot be regarded as a plane wave. Unlike conventional MIMO, which requires an array of receiving antennas, this method is more like MISO, where the signal is directed to a particular receiver. This proposed methodology is different from the transmit diversity techniques based on reciprocity presented in [3-10], as the effects of antenna mutual coupling and other near field effects are taken into account in the present methodology. The present methodology works over a finite bandwidth which may cover the frequency corresponding to the up and the down links. The goal here is to select a set of weights that will induce large currents at a specific receiver, while simultaneously the currents on the other receivers would be canceled. This is very convenient for mobile systems where it may be difficult to place multiple antennas for receptions.

The objective of the present method is to enhance the signal strength rather than the power because we are dealing with near-field environments. In a near-field environment, it is necessary to deal with the Poynting vector, which requires knowledge of both the electric and the magnetic fields or, in other words, the voltage and the current at the feed points of the elements of the transmit antenna array. In a near field environment, since the port currents at the antenna are determined by the electromagnetic environment, optimization of the received power is not possible for a realistic environment, as it changes with time.

This methodology is always applicable as long as the number of transmitting antennas $\mathrm{N}$ is greater than or equal to the number of receivers $M$. On the other hand, if the number of receivers exceeds the number of transmitting antennas $(M>N)$, it may not be possible to achieve a perfect match (namely simultaneously maximizing the induced current at pre-selected receivers, with practically zero current induced on the rest of the receivers). These statements will be illustrated through numerical examples. Also, using the polarization properties, one can enhance the signal strength at a particular receiver while simultaneously minimizing it at the other receivers.

In section 2, the principles of the signal enhancement methodology through adaptivity on transmit is reviewed. Section 3 discusses the polarization properties. In section 4 some numerical examples which have been simulated using the WIPL-D code [17] are presented. This paper does not address how the actual communication takes place and what type of modulation and pulse widths are used, but rather treat the feasibility of the concept. Conclusions follow in section 5 .

\section{Signal enhancement methodology through adaptivity on transmit}

In this procedure, one simultaneously employs the principle of reciprocity and the concept of adaptivity on transmit. The spatial diversity of fixed proximate transmitting antennas permits signals transmitted from a base station to be directed to a pre-selected mobile station without worrying about the presence of other near-field scatterers or the existence of a multipath environment. To illustrate the methodology for $\mathrm{N}$ transmitting and $\mathrm{M}$ independent disjoint mobile receiving antennas operating at the same frequency $f_{0}$, consider the communication 
between a base station with two transmitting antennas $\left(T_{1}\right.$ and $\left.T_{2}\right)$ and two independent mobile receiving antennas $\left(R_{1}\right.$ and $R_{2}$ ) that is depicted in Figure 1. Let $V_{T_{1}}^{R_{1}}$ and $V_{T_{2}}^{R_{1}}$ be the induced voltages on the load resistances located at the feed points of two transmitting antennas $\mathrm{T}_{1}$ and $\mathrm{T}_{2}$, when the receiving antenna $\mathrm{R}_{1}$ transmits with an excitation voltage of $1 \mathrm{~V}$. Here, the superscript $\mathrm{R}_{1}$ Here, the superscript $R_{1}$ is transmitting and the two transmit antennas $T_{1}$ and $T_{2}$ are operating in the receive mode. Thus the subscript denotes the receiving element whereas the superscript specifies the transmitting element. If the known load impedances at the two transmit antennas are $Z_{T_{1}}$ and $Z_{T_{2}}$, then the currents induced at the feed points of the two transmit antennas are $I \frac{R_{1}}{T_{1}}=V \frac{R_{1}}{T_{1}} / Z_{T_{1}} \quad$ and $I \frac{R_{1}}{T_{2}}=V \frac{R_{1}}{T_{2}} / Z_{T_{2}}$

Similarly, when receiving antenna $\mathrm{R}_{2}$ transmits with an applied input voltage of $1 \mathrm{~V}$, then the respective voltages $V \frac{R_{2}}{T_{1}}$ and $V \frac{R_{2}}{T_{2}}$ induced in transmitting antennas $\mathrm{T}_{1}$ and $\mathrm{T}_{2}$ are known. The superscript $\mathrm{R}_{2}$ corresponds to the voltages that are induced in the two transmitting antennas operating in the receive mode when receiving antenna $R_{2}$ is transmitting. So now the currents induced at the two transmit antennas are $I \frac{R_{2}}{T_{1}}=V \frac{R_{2}}{T_{1}} / Z_{T_{1}} \quad$ and $I \frac{R_{2}}{T_{2}}=V \frac{R_{2}}{T_{2}} / Z_{T_{2}}$. Using these four currents $\left(I \frac{R_{1}}{T_{1}}\right.$, $I \frac{R_{1}}{T_{2}}, I \frac{R_{2}}{T_{1}}$ and $\left.I \frac{R_{2}}{T_{2}}\right)$, it is possible to find a set of corresponding weighted excitations $\left(W_{R_{1}}^{T_{1}}, W_{R_{1}}^{T_{2}}, W_{R_{2}}^{T_{1}}\right.$ and $W_{R_{2}}^{T_{2}}$ ) to be applied at the transmitting antennas so that the induced current can be simultaneously maximized at receiving antennas $\mathrm{R}_{1}$

and minimized in receiving antenna $R_{2}$ and vice versa based on the principles of reciprocity. When these weights are used in pairs as excitations on each of the two transmitting antennas, then one will observe that excitations with the following weighting
$W_{R_{1}}^{T_{1}}$ and $W_{R_{1}}^{T_{2}}$, will enhance the signal strength at the receiving antenna $\mathrm{R}_{1}$ while minimizing the signal strength at receiving antenna $\mathrm{R}_{2}$. The subscript on each $W$ specifies the receiving antenna element at which the signal strength is enhanced. Similarly, if $W_{R_{2}}^{T_{1}}$ and $W_{R_{2}}^{T_{2}}$ are used as excitations on the two transmitting antennas, then this will enhance the signal strength at receiving antenna $R_{2}$ while minimizing the signal strength at receiving antenna $\mathrm{R} 1$.

Through the application of the reciprocity principle, it is now illustrated how this can be accomplished. Consider the system represented in Figure 1 and assume that receiving antenna $R_{1}$ is transmitting with a $1 \mathrm{~V}$ excitation. Then the induced currents at the loads located at the feed points of the two transmitting antennas will be $I \frac{R_{1}}{T_{1}}$ and $I \frac{R_{1}}{T_{2}}$. The excitation at the receiving antenna $\mathrm{R}_{1}$ will also induce a voltage at receiving antenna $R_{2}$, which is ignored because it is superfluous to this discussion. This does not mean that this induced voltage is small, but it does not enter into the theory! Now exciting transmitting antenna $\mathrm{T}_{1}$ with $1 \mathrm{~V}$ will induce currents $I \frac{R_{1}}{T_{1}}$ and $I \frac{R_{1}}{T_{2}}$, respectively, at the loads located at the feed points of the two receiving antennas. The superscript $\mathrm{T}_{1}$ indicates that in this case only transmitter $\mathrm{T}_{1}$ is active. Moreover, the $1 \mathrm{~V}$ excitation of transmitter $\mathrm{T}_{1}$ also induces a current at transmitter $\mathrm{T}_{2}$ that is not germane to this development. Now if one applies the principle of reciprocity between the excitation voltages and currents of the two feed ports corresponding to transmitting antenna $T_{1}$ and receiving antenna $R_{1}$, one observes that the respective currents are related by

$$
I \frac{R_{1}}{T_{1}}=I \frac{T_{1}}{R_{1}} .
$$

for $1 \mathrm{~V}$ excitations. Similarly, if the reciprocity principle is applied to the feed ports of transmitting antenna $T_{1}$ and receiving antenna $R_{1}$, then 


$$
I \frac{R_{2}}{T_{1}}=I \frac{T_{1}}{R_{2}}
$$

Therefore, exciting the transmitting antenna $\mathrm{T}_{1}$ with voltage $W^{T_{1}}$ in (1) and (2) induces currents equal to $W^{T_{1}} I_{T_{1}}^{R_{1}}$ at receiving antenna $\mathrm{R}_{1}$ and $W^{T_{1}} I_{T_{1}}^{R_{2}}$ at receiving antenna $\mathrm{R}_{2}$, by reciprocity applied to the respective port of the transmitting and receiving antennas.

If we now excite receiving antenna $\mathrm{R}_{1}$ with $1 \mathrm{~V}$, then currents $I_{T_{1}}^{R_{2}}$ and $I_{T_{2}}^{R_{2}}$ are induced at transmitting antennas $\mathrm{T}_{1}$ and $\mathrm{T}_{1}$, respectively, and the induced current in receiving antenna $\mathrm{R}_{1}$ is ignored, as it is not germane to the present discussions. Recall that the superscript $R_{2}$ on the currents implies that receiving antenna $R_{2}$ is transmitting. Now exciting transmitting antenna $\mathrm{T} 2$ with $1 \mathrm{~V}$ induces currents $I_{T_{1}}^{R_{2}}$ and $I_{T_{1}}^{R_{2}}$, respectively, at the loads located at the feed points of the two receiving antennas, as well as an inconsequential current at the inactive transmitter $\mathrm{T}_{1}$. Now if one applies the principle of reciprocity between the excitation voltages and currents of the two feed ports corresponding to transmitting antennas $T_{2}$ and receiving antennas $R_{1}$, then the respective currents are related by

$$
I_{T_{2}}^{R_{1}}=I_{R_{1}}^{T_{2}}
$$

when $\mathrm{T}_{1}$ and $\mathrm{R}_{2}$ are excited with $1 \mathrm{~V}$. Similarly, if one applies the same principle of reciprocity between the feed ports of transmitting antennas $\mathrm{T}_{2}$ and receiving antennas $\mathrm{R}_{2}$, then one will obtain

$$
I_{T_{2}}^{R_{2}}=I_{R_{2}}^{T_{2}}
$$

Therefore, exciting transmitting antenna $\mathrm{T}_{1}$ with voltage $W^{T_{2}}$ and applying the principle of reciprocity to the respective ports of the transmitting and the receiving antennas will induce currents equal to $W^{T_{2}} I_{T_{2}}^{R_{1}}$ at receiving antenna $\mathrm{R} 1$ and $W^{T_{2}} I_{T_{2}}^{R_{2}}$ at receiving antenna $R_{2}$.
Next, the principle of superposition is applied to modify some of these induced currents. Suppose transmitting antennas $\mathrm{T}_{1}$ and $\mathrm{T} 2$ are excited with voltages $W_{R_{1}}^{T_{1}}$ and $W_{R_{1}}^{T_{2}}$, respectively. The subscript R1 symbolically specifies the goal of maximizing the induced current in receiving antenna $R_{1}$ while ensuring the current in receiving antenna $R_{2}$ is practically zero. Assume that this maximum current is 1A. Under these conditions, the desired total currents induced in receiving antennas $\mathrm{R}_{1}$ and $\mathrm{R}_{1}$ respectively are

$$
\begin{aligned}
& W_{R_{1}}^{T_{1}} I_{T_{1}}^{R_{1}}+W_{R_{1}}^{T_{2}} I_{T_{2}}^{R_{1}}=1, \\
& W_{R_{1}}^{T_{1}} I_{T_{1}}^{R_{2}}+W_{R_{1}}^{T_{2}} I_{T_{2}}^{R_{2}}=0 .
\end{aligned}
$$

Similarly, it is possible to choose a set of excitations, $W_{R_{2}}^{T_{1}}$ and $W_{R_{2}}^{T_{2}}$, to be applied to the transmitting antennas $T_{1}$ and $T_{2}$, such that no current is induced in receiving antenna $\mathrm{R}_{1}$ and the current induced at receiving antenna $\mathrm{R}_{2}$ is $1 \mathrm{~A}$. Under these conditions, the total current induced in receiving antenna $\mathrm{R}_{1}$ will be

$$
\begin{aligned}
& W_{R_{2}}^{T_{1}} I_{T_{1}}^{R_{1}}+W_{R_{2}}^{T_{2}} I_{T_{2}}^{R_{1}}=0, \\
& W_{R_{2}}^{T_{1}} I_{T_{1}}^{R_{2}}+W_{R_{2}}^{T_{2}} I_{T_{2}}^{R_{2}}=1 .
\end{aligned}
$$

Equations (5)-(8) can be written more compactly in a matrix form as

$$
\left[\begin{array}{cc}
I_{T_{1}}^{R_{1}} & I_{T_{2}}^{R_{1}} \\
I_{T_{1}}^{R_{2}} & I_{T_{2}}^{R_{2}}
\end{array}\right]\left[\begin{array}{ll}
W_{R_{1}}^{T_{1}} & W_{R_{2}}^{T_{1}} \\
W_{R_{1}}^{T_{2}} & W_{R_{2}}^{T_{2}}
\end{array}\right]=\left[\begin{array}{ll}
1 & 0 \\
0 & 1
\end{array}\right] .
$$

By using (9), one can solve for an a priori set of excitations that will direct the signal to a pre-selected receiver by vectorially combining the signal from the two transmitting receivers. The excitations are obtained by inverting the current matrix in (9) to obtain 


$$
\left[\begin{array}{cc}
W_{R_{1}}^{T_{1}} & W_{R_{2}}^{T_{1}} \\
W_{R_{1}}^{T_{2}} & W_{R_{2}}^{T_{2}}
\end{array}\right]=\left[\begin{array}{cc}
I_{T_{1}}^{R_{1}} & I_{T_{2}}^{R_{1}} \\
I_{T_{1}}^{R_{2}} & I_{T_{2}}^{R_{2}}
\end{array}\right]^{-1}\left[\begin{array}{ll}
1 & 0 \\
0 & 1
\end{array}\right] .
$$

The caveat here is if transmitting antennas $\mathrm{T}_{1}$ and $\mathrm{T}_{2}$ are excited by $W_{R_{1}}^{T_{1}}$ and $W_{R_{1}}^{T_{2}}$, respectively, then the scattered near-field electromagnetic signals will be vectorially additive at the load, which is located at the feed point of receiving antenna $\mathrm{R}_{1}$, and would be destructive at the feed point of receiving antenna $\mathrm{R}_{2}$ In contrast, if one applies $W_{R_{2}}^{T_{1}}$ and $W_{R_{2}}^{T_{2}}$ to transmitting antennas $T_{1}$ and $T_{2}$, then the received electromagnetic signal will be vectorially destructive at the load, which is located at the feed point of receiving antenna $R_{1}$, and will be vectorially additive at the feed point of receiving antenna $R_{1}$, generating a large value for the induced load current.

In short, by knowing the voltages that are induced in each of the transmitting antennas by every receiver, it is possible to select a set of weights based on reciprocity that will induce large currents at a specific receiving antenna. This relationship, based on the principles of reciprocity and superposition, can be applied only at the terminals of the transmitting and receiving antennas. This also assumes that there exists a two way link between the transmitter and the receiver. Furthermore, this principle of directing the signal energy to a pre-selected receiver is independent of the sizes and shapes of the receiving antennas and the near field environments.

\section{Exploitation of the Polarization properties in the Proposed Methodology}

Polarization diversity at the transmit antennas can also be utilized as shown in Figure 2. Either an antenna transmitting different linear polarizations can be switched on or one can be dealing with circular polarization. However, the principles are the same in both cases. Using the polarization properties, one can also enhance the signal strength at a particular receiver while simultaneously minimizing it at the other receivers. For the example in Figure 2, each of the receivers can have arbitrary polarization whereas the transmitter can switch to either vertical or horizontal polarization. Again the mathematical principles to direct the signal to a pre-selected receiver and producing zero signals at the others follow exactly as presented in the previous section. These principles are now explained though numerical simulations.

\section{Numerical Simulations}

For the first example, three transmitting and three receiving antennas operating in free space is considered. Two kinds of antennas are chosen as possible candidates for either transmitting or receiving; helical and biconical antennas. Helixes produce circular polarization but they are not as broadband as the biconical antennas. However, the bicones produce linear polarization. For the second example, a triad of three transmitting helical antennas and a triad of three receiving helical antennas which are placed inside a finite conducting cylinder are used. In the final example, four receiving antennas and two transmitting antennas are chosen. Two cases are considered for this example. In the first case these antennas are placed in free space, and in the second case they are put inside a finite conducting cylinder with a metal partition so that there is no line of sight propagation of the direct path.

\section{Example 1.}

Consider three transmitting helical antennas $\mathrm{A}_{1}$, $\mathrm{A}_{2}$, and $\mathrm{A}_{3}$, located at a base station. Each helical antenna has a circumference $\mathrm{C}=0.3 \mathrm{~m}$. The diameter of the helix $\mathrm{D}=\mathrm{C} / \pi=0.0955 \mathrm{~m}$, pitch angle $a=13^{\circ}$, the spacing between turns $\mathrm{S}=\mathrm{C} \times \tan (\alpha)$, length of one turn $\mathrm{L}=$ $\sqrt{C^{2}+S^{2}}=0.3079 \mathrm{~m}$, number of turns $\mathrm{n}=10$, and the axial length $\mathrm{A}=\mathrm{n} \times \mathrm{S}=0.6926 \mathrm{~m}$. The operating frequency is $1 \mathrm{GHz}$. Next three receiving antennas marked as $\mathrm{A}_{4}, \mathrm{~A}_{5}$, and $\mathrm{A}_{3}$ in Figure 3 are considered. Dimension of the 
receiving antennas are the same and they are separated from the transmitters by a distance of 6 m. All of the six antennas are centrally loaded with $140 \Omega$.

First consider maximizing the induced currents in the receiving antenna $\mathrm{A} 4$. The receiving antenna $\mathrm{A}_{4}$ is excited with $1 \mathrm{~V}$, which induces currents in receiving antennas $\mathrm{A}_{5}$ and $\mathrm{A}_{6}$ and transmitting antennas $\mathrm{A}_{1}, \mathrm{~A}_{2}$, and $\mathrm{A}_{3}$. These currents are computed by the electromagnetic analysis code WIPL-D [17]. In turn, these induced currents generate voltages across the loads of the other five centrally loaded helixes. The induced currents at transmitting antennas $\mathrm{A}_{1}, \mathrm{~A}_{2}$, and $\mathrm{A}_{3}$ are $I_{A_{1}}^{A_{4}}, \quad I_{A_{2}}^{A_{4}}$ and $I_{A_{3}}^{A_{4}}$, respectively. As noted earlier, the currents induced in $\mathrm{A}_{5}$ and $\mathrm{A} 6$ are not considered, as they are not relevant in the present discussions. The induced currents have been obtained using the WIPL-D code [17]. Next, when $\mathrm{A} 5$ is excited with $1 \mathrm{~V}$, it induces the currents $I_{A_{1}}^{A_{5}}, I_{A_{2}}^{A_{5}}$, and $I_{A_{3}}^{A_{5}}$ on transmitting antennas $\mathrm{A}_{1}, \mathrm{~A}_{2}$, and $\mathrm{A}_{3}$, respectively. Similarly, exciting receiver A6 with $1 \mathrm{~V}$ induces currents $I_{A_{1}}^{A_{6}}, I_{A_{2}}^{A_{6}}$, and $I_{A_{3}}^{A_{6}}$ in $\mathrm{A}_{1}, \mathrm{~A}_{2}$, and $\mathrm{A}_{3}$, Based on the available information, the claim is that one can choose a set of complex voltages $\left\{W_{A_{i}}^{A_{1}}, W_{A_{i}}^{A_{2}}\right.$ and $\left.W_{A_{i}}^{A_{3}}\right\}$, for $\mathrm{i}=4,5$, or 6 , which when exciting the three transmitting antennas will result in an additive combination of the electromagnetic fields at receiving antenna $\mathrm{A}_{i}$, while inducing zero currents at the other two receiving antennas. The receiver currents then would be

$I^{A_{4}}=W_{A_{4}}^{A_{1}} I_{A_{1}}^{A_{4}}+W_{A_{4}}^{A_{2}} I_{A_{2}}^{A_{4}}+W_{A_{4}}^{A_{3}} I_{A_{3}}^{A_{4}}$ (at receiver A1)

$I^{A_{5}}=W_{A_{4}}^{A_{1}} I_{A_{1}}^{A_{5}}+W_{A_{4}}^{A_{2}} I_{A_{2}}^{A_{5}}+W_{A_{4}}^{A_{3}} I_{A_{3}}^{A_{5}}$ (at receiver $\mathrm{A} 1$ ),

$I^{A_{6}}=W_{A_{4}}^{A_{1}} I_{A_{1}}^{A_{6}}+W_{A_{4}}^{A_{2}} I_{A_{2}}^{A_{6}}+W_{A_{4}}^{A_{3}} I_{A_{3}}^{A_{6}}$ (at receiver A1)

The objective now is to select the excitations $W_{A_{j}}^{A_{i}}$ for each $j$ of $\{1,2$ or 3$\}$ in such a fashion that the received currents are maximal at receiving antenna $\mathrm{A} i$ and zero at the other receiving antennas.

To determine the weight vectors that should induce the maximum current to only one receiving antenna $\mathrm{A}_{i}(i=3,4$ and 5$)$, solve

$$
\left[\begin{array}{ccc}
I_{A_{1}}^{A_{4}} & I_{A_{2}}^{A_{4}} & I_{A_{3}}^{A_{4}} \\
I_{A_{1}}^{A_{5}} & I_{A_{2}}^{A_{5}} & I_{A_{3}}^{A_{5}} \\
I_{A_{1}}^{A_{6}} & I_{A_{2}}^{A_{6}} & I_{A_{3}}^{A_{6}}
\end{array}\right]\left[\begin{array}{lll}
W_{A_{4}}^{A_{1}} & W_{A_{5}}^{A_{1}} & W_{A_{6}}^{A_{1}} \\
W_{A_{4}}^{A_{2}} & W_{A_{5}}^{A_{1}} & W_{A_{6}}^{A_{1}} \\
W_{A_{4}}^{A_{3}} & W_{A_{5}}^{A_{1}} & W_{A_{6}}^{A_{1}}
\end{array}\right]=\left[\begin{array}{lll}
1 & 0 & 0 \\
0 & 1 & 0 \\
0 & 0 & 1
\end{array}\right]
$$

using the least square method to obtain

$$
\begin{aligned}
& {\left[\overrightarrow{W_{4}}, \overrightarrow{W_{5}}, \overrightarrow{W_{6}}\right]=\left[\begin{array}{l}
W_{A_{4}}^{A_{1}} W_{A_{5}}^{A_{1}} W_{A_{6}}^{A_{1}} \\
W_{A_{4}}^{A_{2}} W_{A_{5}}^{A_{2}} W_{A_{6}}^{A_{2}} \\
W_{A_{4}}^{A_{3}} W_{A_{5}}^{A_{3}} W_{A_{6}}^{A_{3}}
\end{array}\right]} \\
& =\left[\begin{array}{lll}
0.323+4.636 j-0.368+0.509 j & 0.318-0.631 j \\
2.217+1.405 j & -2.302-1.432 j & 2.188+1.390 j \\
0.322-0.634 j-0.360+0.504 j & 0.309+4.613 j
\end{array}\right]
\end{aligned}
$$

To demonstrate the feasibility of this methodology, the voltages $\left(\overrightarrow{W_{4}}\right)$ are used as excitation inputs in the WIPL-D electromagnetic code [17] to compute the induced currents on $\mathrm{A}_{4}, \mathrm{~A} 5$, and $\mathrm{A}_{6}$ as

$I^{A_{4}}=1-0.001 j, I^{A_{5}}=-0.001+0.001 j, I^{A_{6}}=0.001-0.001 j$

where $R_{A_{1}}=R_{A_{2}}=R_{A_{3}}=140 \Omega$ and all currents are multiplied by $10^{-3} \mathrm{~A}$. Clearly, all the electromagnetic signals are vectorially additive at receiving antenna $\mathrm{A} 4$, because the currents are practically zero at the feeds of receiving antennas A5 and A6. Similarly, to direct the signals to A5, one can use the computed voltages $\overrightarrow{W_{5}}$ in WIPL-D to find the feed currents as

$$
I^{A_{4}}=0, I^{A_{5}}=1.0, I^{A_{6}}=0
$$

which clearly shows that the induced energy can be directed to receiving antenna As while producing no appreciable induced currents at the other two receiving antennas ( $\mathrm{A}_{4}$ and $\left.\mathrm{A} 6\right)$. Finally, to direct the signal from the transmitting antennas to $A_{6}$, one can use the computed voltages $\overrightarrow{W_{6}}$ in WIPL-D to find the feed currents as 


$$
I^{A_{4}}=-0.001, I^{A_{5}}=-0.001, I^{A_{6}}=1.0 .
$$

This clearly demonstrates that by appropriately choosing the magnitude of the excitations at the different transmitting antennas it is possible to direct the signal so that it vectorially adds up at a pre-selected receiving antenna.

Next, the behavior of the magnitude of the currents on $\mathrm{A}_{4}, \mathrm{~A}_{4}$ and $\mathrm{A}_{6}$ as a function of frequency is analyzed to observe what is the useful bandwidth of the proposed methodology. So one fixes the weights at the transmitting antennas which have been evaluated at $1 \mathrm{GHz}$ and then can use the same weights at other frequencies to observe how well this methodology works. The induced currents at each of the receivers are simulated in Figs. 4-6 over the $12.0 \%$ bandwidth from $0.94 \mathrm{GHz}$ to $1.06 \mathrm{GHz}$ when using the three set of frequency independent voltages $\left[\overrightarrow{W_{4}}, \overrightarrow{W_{5}}, \overrightarrow{W_{6}}\right]$ obtained for $1 \mathrm{GHz}$. As indicated in Figure 4 for $\overrightarrow{W_{4}}$, the induced currents at the other receivers are down by a factor of 4.3 in the lower frequency and by a factor of 4.8 at the upper frequency. For the middle receiver, the induced currents at the other receivers are down by a factor of 10 at the higher frequency end and by a factor of 12 at the lower frequency end points as shown in Figure 5. Finally the result in figure 6 is just the reverse of Figure 4 as the six helical antennas have an axis of symmetry.

The useful bandwidth of this methodology can be increased by using biconical antennas instead of helixes, as demonstrated next. The six helical antennas of Figure 3 are replaced by six biconical antennas as shown in Figure 7. The biconical antenna has an angle of $90^{\circ}$ so that its input impedance is approximately $106 \Omega$. In this case, one can now sweep the frequency from $1.5 \mathrm{GHz}$ to $1.7 \mathrm{GHz}$ generating a $12.5 \%$ bandwidth, and the excitations are solved for in a similar fashion as outlined above. As indicated in Figure 8, for a $12.5 \%$ bandwidth centered at $1.6 \mathrm{GHz}$, the induced currents at the other receivers are down by a factor of 3 at the lower frequency end and by a factor of 5.7 at the upper frequency end. For the center receiver, the induced currents at the other receivers are down by a factor of 3 at the higher and by a factor of 6 at the lower frequency end points as shown in Figure 9. Finally the result for the third receiver is identical to that of Figure 8 as the six antennas have an axis of symmetry.

\section{Example 2.}

Now, the six helical antennas are placed inside a concentric perfectly conducting cylinder as shown in Figure 10. The dimension of the conducting cylinder is $7.8 \mathrm{~m} \times 4.8 \mathrm{~m} \times 1.2 \mathrm{~m}$. The transmitting and the receiving antenna sets are separated by $6 \mathrm{~m}$ and the inter-element spacing within each set is $1.5 \mathrm{~m}$. All the six antennas are loaded by $140 \Omega$.

Along the same line, one can also choose a set of excitation voltages as follows

$$
\begin{aligned}
& {\left[\overrightarrow{W_{4}}, \overrightarrow{W_{5}}, \overrightarrow{W_{6}}\right]=\left[\begin{array}{lll}
W_{A_{4}}^{A_{1}} & W_{A_{5}}^{A_{1}} & W_{A_{6}}^{A_{1}} \\
W_{A_{4}}^{A_{2}} & W_{A_{5}}^{A_{2}} & W_{A_{6}}^{A_{2}} \\
W_{A_{4}}^{A_{3}} & W_{A_{5}}^{A_{3}} & W_{A_{6}}^{A_{3}}
\end{array}\right]} \\
& =\left[\begin{array}{rr}
-1.359-0.995 j-0.803+0.326 j & 0.333-0.394 j \\
-0.805+0.328 j-0.989-0.256 j & -0.831+0.335 j \\
0.336-0.397 j-0.830+0.341 j-1.473-0.994 j
\end{array}\right]
\end{aligned}
$$

so that the energy can be directed to a pre-selected receiver.

For the three sets of excitation voltages Table 1 shows that the signal can be directed to each receiver.

Table 1. Complex values of the currents measured at the three receiving antennas marked as 4,5 and 6 for three different choices of excitations.

\begin{tabular}{c|ccc}
$\begin{array}{c}\text { By the excitation } \\
\text { voltages }\end{array}$ & $I^{A_{4}}$ & $I^{A_{5}}$ & $I^{A_{6}}$ \\
\hline $\overrightarrow{W_{4}}$ & $1.0013-\mathrm{j} 0.0008 \mathrm{j}$ & $-0.0023-\mathrm{j} 0.0010$ & $0.0004+\mathrm{j} 0.0009$ \\
\hline $\overrightarrow{W_{5}}$ & $-0.0004+\mathrm{j} 0.0017$ & $1.0016+\mathrm{j} 0.0001$ & $-0.0009-\mathrm{j} 0.0029$ \\
\hline $\overrightarrow{W_{6}}$ & $-0.0022-\mathrm{j} 0.0010$ & $0.0031+\mathrm{j} 0.0042$ & $0.9970+\mathrm{j} 0.0007$ \\
\hline
\end{tabular}

Next, the total power fed to each transmit antenna is calculated which will result in the received power to a single receiving antenna. The various input and 
output power requirements are presented in Table 2 . (The numbers are rounded to 4 decimal places). The first column displays the magnitude of the total input power required at the three transmitting antennas and the second column provides the received power at the individual receiving antennas caused by the three sets of excitation voltages. The received power for each excitation is practically the same, $50 \mu \mathrm{W}$, because the induced current at the receiving antenna is $1 \mathrm{~mA}$.

Table 2. The magnitude of the input power at the transmitting antennas and the received power at the receiving antennas for the three choices of the excitations.

\begin{tabular}{|c|c|c|}
\hline $\begin{array}{c}\text { By the } \\
\text { excitation } \\
\text { voltages }\end{array}$ & $\begin{array}{c}\text { linput } \\
\text { Power] } \\
{[\mathrm{mW}]}\end{array}$ & $\begin{array}{c}\text { Received } \\
\text { Power[ } \mu \mathrm{W}]\end{array}$ \\
\hline $\overrightarrow{W_{4}}$ & 19.0218 & 50.1352 \\
\hline $\overrightarrow{W_{5}}$ & 12.2887 & 50.1637 \\
\hline $\overrightarrow{W_{6}}$ & 20.8739 & 49.7052 \\
\hline TOTAL & 52.1844 & 150.0041 \\
\hline
\end{tabular}

Next the eigenvectors of the transfer function in this transmit/receive system for a conventional MIMO system is determined. The various transfer functions can be defined as

$$
\begin{aligned}
& {\left[\begin{array}{c}
I_{A_{4}} \\
I_{A_{5}} \\
I_{A_{6}}
\end{array}\right]=\left[\begin{array}{lll}
H_{11} & H_{12} & H_{13} \\
H_{21} & H_{22} & H_{23} \\
H_{31} & H_{32} & H_{33}
\end{array}\right]\left[\begin{array}{c}
V_{A_{1}} \\
V_{A_{2}} \\
V_{A_{3}}
\end{array}\right]} \\
& {[H]=\left[\begin{array}{lll}
H_{11} & H_{12} & H_{13} \\
H_{21} & H_{22} & H_{23} \\
H_{31} & H_{32} & H_{33}
\end{array}\right]} \\
& {\left[\begin{array}{lll}
\left.\frac{I_{A_{4}}^{A_{1}}}{V_{A_{1}}}\right|_{A_{2}}=V_{A_{3}}=0 & \left.\frac{I_{A_{4}}^{A_{2}}}{V_{A_{2}}}\right|_{A_{A_{1}}}=V_{A_{3}}=0 & \left.\frac{I_{A_{4}}^{A_{3}}}{V_{A_{3}}}\right|_{V_{A_{1}}}=V_{A_{2}}=0 \\
\left.\frac{I_{A_{5}}^{A_{1}}}{V_{A_{1}}}\right|_{A_{2}}=V_{A_{3}}=0 & \left.\frac{I_{A_{5}}^{A_{2}}}{V_{A_{2}}}\right|_{A_{1}}=V_{A_{3}}=0 & \left.\frac{I_{A_{5}}^{A_{2}}}{V_{A_{3}}}\right|_{V_{A_{1}}}=V_{A_{2}}=0 \\
\left.\frac{I_{A_{6}}^{A_{1}}}{V_{A_{1}}}\right|_{V_{12}}=V_{A_{3}}=0 & \left.\frac{I_{A_{6}}^{A_{2}}}{V_{A_{2}}}\right|_{V_{A 1}}=V_{A_{3}}=0 & \left.\frac{I_{A_{6}}^{A_{2}}}{V_{A_{3}}}\right|_{A_{11}}=V_{A_{2}}=0
\end{array}\right]}
\end{aligned}
$$

$I_{A_{1}}^{A_{1}}$ is the induced current at the feed points of the receiving antennas $\mathrm{A} 4$, when the transmitting antenna $A_{1}$ operates with an excitation voltage of
$V_{A_{1}}$ V. Thus the subscript denotes the receiving element whereas the superscript specifies the transmitting element.

The various transfer function can then be obtained as

$$
\begin{aligned}
& {[H]=\left[\begin{array}{ccc}
\frac{I_{A_{4}}^{A_{1}}}{1} & \frac{I_{A_{4}}^{A_{2}}}{1} & \frac{I_{A_{4}}^{A_{3}}}{1} \\
\frac{I_{A_{5}}^{A_{1}}}{1} & \frac{I_{A_{5}}^{A_{2}}}{1} & \frac{I_{A_{5}}^{A_{3}}}{1} \\
\frac{I_{A_{6}}^{A_{1}}}{1} & \frac{I_{A_{6}}^{A_{2}}}{1} & \frac{I_{A_{6}}^{A_{3}}}{1}
\end{array}\right]} \\
& =\left[\begin{array}{rrr}
-0.2777+0.2807 j & -0.1698-0.2768 j & 0.2368+0.0957 j \\
-0.1688-0.2753 j & -0.4407+0.4591 j & -0.1552-0.2733 j \\
0.2351+0.0962 j & -0.1527-0.2734 j & -0.2734+0.2619 j
\end{array}\right] \\
& =\left[\begin{array}{rrr}
-0.1688-0.2753 j & -0.4407+0.4591 j & -0.1552-0.2733 j \\
0.2351+0.0962 j & -0.1527-0.2734 j & -0.2734+0.2619 j
\end{array}\right]
\end{aligned}
$$

In a conventional MIMO, three independent orthogonal beams are generated by performing a singular value decomposition (SVD) of $[\mathrm{H}]$ to form $[U]^{H}[H][V]=[\Sigma]$. Therefore,

$$
[H]=[U][\Sigma][V]^{H}
$$

where [U] is a $3 \times 3$ unitary matrix whose columns are the eigenvectors of $[H][H]^{H},[\Sigma]$ is the $3 \times 3$ diagonal matrix with the singular values, $\sigma_{i}^{2}$, of $[\mathrm{H}]$ written through

$$
[\Sigma]=\left[\begin{array}{ccc}
0.8834 & 0 & 0 \\
0 & 0.5417 & 0 \\
0 & 0 & 0.4082
\end{array}\right]
$$

and [V]is the $3 \times 3$ unitary matrix whose columns are the eigenvectors of $[H]^{H}[H]$ and are given by

$$
[V]=\left[\begin{array}{ccc}
0.3739 & 0.7547 & 0.5391 \\
-0.6471+0.5484 j & 0.0392-0.0208 j & 0.3939-0.3512 j \\
0.3750-0.0040 j & -0.6540+0.0284 j & 0.6554-0.0370 j
\end{array}\right]
$$

The superscript $H$ denotes the conjugate transpose of a matrix. Then the eigenvectors of $[H]^{H}[H]$ will be used as excitation voltage sets. Table 3 shows the total input power and received power for the eigen-modes when the eigenvector voltage sets are used as excitations. Note that the singular values and the received power for each of the eigen-mode in a conventional MIMO caused by the eigenvector sets 
have a relationship given by

$$
\frac{\sigma_{2}^{2}}{\sigma_{1}^{2}}, \frac{\sigma_{3}^{2}}{\sigma_{1}^{2}}=\frac{P_{\text {received by } 2^{n d}}}{P_{\text {received by } 1^{\text {st }}}}, \frac{P_{\text {received by } 2^{\text {nd }}}}{P_{\text {received by } 1^{\text {st }}}}
$$

Therefore, to induce the same amount of the received power $50 \mathrm{~mW}$ through each mode in a conventional MIMO, in contrast to the same power received at each of the individual receivers obtained by the current procedure is presented in Table 3.

Table 3. The magnitude of the input power at the transmitting antennas and the received power at the receiving antennas for three choices of excitations using the six helical antenna transmit/receive system inside of the cylinder.

\begin{tabular}{|c|c|c|c|c|c|}
\hline \multicolumn{3}{|c|}{$\begin{array}{l}\text { Using the eigenvector } \\
\text { excitation sets in MIMO }\end{array}$} & \multicolumn{3}{|c|}{ By using reciprocity, the } \\
excitation sets
\end{tabular}

It is seen that using reciprocity, the dynamic range of the input power associated with each mode of transmission is much smaller than the ones in a conventional MIMO.

\section{Example 3.}

Consider a situation where the number of receiving antennas is greater than the number of transmitting antennas, which is different from the previous examples where they have been equal. How the polarization properties are useful for the signal enhancement in this situation is examined.

Consider two transmitting antennas and four receiving antennas. All of them have the same polarization that is a right-hand circular polarization. The dimensions of the antennas are same as in the previous examples operating at 1 $\mathrm{GHz}$. Antennas are located as described in Figure 12. The transmitting and the receiving antenna sets are separated by $12 \mathrm{~m}$, the inter-element spacing of the receiving antennas is $1.5 \mathrm{~m}$ and the inter-element spacing of the transmitting antennas is $1.8 \mathrm{~m}$. Since the number of transmitters is less than the number of receivers, it may not be possible to direct the signals to a particular receiver and cancel it at the other receivers. Table 4 presents the magnitudes of the currents at the four receiving antennas when the two transmitting antennas are simultaneously radiating energy. From Table 4, it is seen that there is approximately a $2.5 \mathrm{~dB}$ difference in the signal levels between the desired receivers and the neighboring one.

Table 4. Magnitudes of the received currents $I^{R_{i}}$ at each of the four receiving antennas without exploiting polarization.

\begin{tabular}{c|cccc}
\hline $\begin{array}{c}\text { By the } \\
\text { excitation } \\
\text { voltages }\end{array}$ & $\left|I^{A_{3}}\right|$ & $\left|I^{A_{4}}\right|$ & $\left|I^{A_{5}}\right|$ & $\left|I^{A_{6}}\right|$ \\
\hline $\overrightarrow{W_{3}}$ & 0.4654 & 0.3448 & 0.0651 & 0.3492 \\
\hline $\overrightarrow{W_{4}}$ & 0.3473 & 0.5382 & 0.3532 & 0.0709 \\
\hline $\overrightarrow{W_{5}}$ & 0.0684 & 0.3559 & 0.5338 & 0.3402 \\
\hline $\overrightarrow{W_{6}}$ & 0.3598 & 0.0741 & 0.3427 & 0.4625 \\
\hline
\end{tabular}

Now the concept of polarization is introduced. Some of the receivers have left-handed helical antennas and some of them have right-handed antennas. For an axial mode helical antenna, the direction of the windings determines the sense of polarization. So in this example the transmission of two orthogonally polarized waves is examined. There are two types of antennas, which are co-located at the base station, and these antennas can be switched. And also users $\mathrm{A}_{3}$ and $\mathrm{A}_{5}$ use a right hand polarization antenna and $\mathrm{A}_{3}$ and $\mathrm{A}_{6}$ has a left hand polarization antenna.

By the first method, when the transmitters are using the R-H polarization mode, excite each mobile receiving antenna which has an $\mathrm{R}-\mathrm{H}$ polarization, $\mathrm{A}_{3}$ and $\mathrm{A} 5$, and measure the currents that are induced at transmitting antennas in the base station. Then, one can choose a set of complex voltages $\left\{W_{A_{i}}^{A_{1}}\right.$ and $\left.W_{A_{i}}^{A_{2}}\right\}$, for $I=3$, or 5 , to direct the transmitted signal to $\mathrm{A}_{3}$ or A5. By using the polarization property, the induced currents at $\mathrm{A}_{4}$ and $\mathrm{A}_{6}$ which have $\mathrm{L}-\mathrm{H}$ polarization, should be zero. The excitations to direct the signal to the receivers 1 and $3(\mathrm{R}-\mathrm{H}$ 
receivers) are as follows,

$$
\begin{aligned}
& {\left[\overrightarrow{W_{3}}, \overrightarrow{W_{5}}\right]=\left[\begin{array}{ll}
W_{A_{3}}^{A_{1}} & W_{A_{5}}^{A_{1}} \\
W_{A_{3}}^{A_{2}} W_{A_{5}}^{A_{2}}
\end{array}\right]} \\
& =\left[\begin{array}{lr}
0.4382-1.6414 j & 0.9224-0.5240 j \\
1.2530-0.8170 j & -1.5067-0.3129 j
\end{array}\right]
\end{aligned}
$$

When the transmitters are in the L-H polarization mode of operation, one can choose a set of complex voltages $\left\{W_{A_{i}}^{A_{1}}\right.$ and $\left.W_{A_{i}}^{A_{2}}\right\}$, for $\mathrm{i}=4$, or 6 , to direct the transmitted signals to $\mathrm{A}_{4}$ or $\mathrm{A}_{6}$. These weights are for the $\mathrm{R}-\mathrm{H}$ receivers $\mathrm{A}_{4}$ and $\mathrm{A}_{6}$ as follows,

$$
\begin{aligned}
& {\left[\overrightarrow{W_{4}}, \overrightarrow{W_{6}}\right]=\left[\begin{array}{l}
W_{A_{4}}^{A_{1}} W_{A_{6}}^{A_{1}} \\
W_{A_{4}}^{A_{2}} W_{A_{6}}^{A_{2}}
\end{array}\right]} \\
& =\left[\begin{array}{rr}
-1.5106-0.3137 j & 1.2336-0.8324 j \\
0.9273-0.5202 j & 0.4306-1.6395 j
\end{array}\right]
\end{aligned}
$$

Using these weights, when the polarization of the desired receiving antenna is the same as that of the transmitting antennas, the received currents at each of the four receiving antennas are shown in Table 5.

Table 5. Magnitudes of the received currents $I^{A_{i}}$ at each of the four receiving antennas

\begin{tabular}{c|cccc}
\hline $\begin{array}{c}\text { By the } \\
\text { exitation } \\
\text { voltages }\end{array}$ & $\left|I^{A_{3}}\right|$ & $\left|I^{A_{4}}\right|$ & $\left|I^{A_{5}}\right|$ & $\left|I^{A_{6}}\right|$ \\
\hline $\overrightarrow{W_{3}}$ & 1.0025 & 0.0794 & 0.0049 & 0.0766 \\
\hline $\overrightarrow{W_{4}}$ & 0.0915 & 0.9999 & 0.0938 & 0.0030 \\
\hline $\overrightarrow{W_{5}}$ & 0.0034 & 0.0901 & 0.9996 & 0.0900 \\
\hline $\overrightarrow{W_{6}}$ & 0.0745 & 0.0056 & 0.0741 & 0.9972 \\
\hline
\end{tabular}

As seen from Table 5, using the specified excitations, one obtains $1 \mathrm{~mA}$ at the receiver 1 , $0.005 \mathrm{~mA}$ at receiver 3 , and $0.08 \mathrm{~mA}$ at the receiver 2 and 4 which have a different polarization. The reason that the current at receiver 2 and 4 are not zero is that the axial ratio of these helical antennas is 1.074 . Theoretically, the formula for axial ratio is

$$
|A R|=\frac{2 N+1}{2 N}
$$

where $N$ is the number of turns. So for this helical antenna AR is 1.05 theoretically. It is indicates that the quality of the circular polarization improves with the number of turns.

Next, when the transmitters are in the $\mathrm{R}-\mathrm{H}$ polarization mode, all the mobile receiving antennas, A3, A4, A5, and A6, are excited. The currents that are induced at the transmitting antennas in the base station are measured which allows one to determine the appropriate weight vectors. For directing the signals to the $j^{\text {th }}$ row. One can choose a set of complex voltages $\left\{W_{A_{i}}^{A_{1}}\right.$ and $\left.W_{A_{i}}^{A_{2}}\right\}$, only for $\mathrm{i}=4$, or 6, which yields in Table 6 as:

Table 6. Magnitudes $I_{R_{i}}$ of the induced currents at each of the four receiving antennas

\begin{tabular}{c|cccc}
\hline $\begin{array}{c}\text { By the } \\
\text { excitation } \\
\text { voltages }\end{array}$ & $\left|I^{A_{3}}\right|$ & $\left|I^{A_{4}}\right|$ & $\left|I^{A_{5}}\right|$ & $\left|I^{A_{6}}\right|$ \\
\hline $\overrightarrow{W_{3}}$ & 0.9910 & 0.0784 & 0.0054 & 0.0757 \\
\hline $\overrightarrow{W_{4}}$ & 0.0900 & 0.9832 & 0.0922 & 0.0035 \\
\hline $\overrightarrow{W_{5}}$ & 0.0044 & 0.0886 & 0.9834 & 0.0886 \\
\hline $\overrightarrow{W_{6}}$ & 0.0737 & 0.0055 & 0.0732 & 0.9857 \\
\hline
\end{tabular}

Next, one considers four receiving and two transmitting antennas that are located inside a conducting cylinder of finite height, with a partition in the middle as shown in Figure 12. In this example there is no direct path of communication and the interaction takes place either through the guided waves or the diffracted waves. Transmitters and receivers are all situated in the near field of the obstacles where beam forming is not possible. Table 7 shows the currents induced at the receivers. Using the L-H polarization one can get similar results. When one uses no polarization, the results are not as good as when the polarization properties are exploited. 
Table 7. Magnitudes $I_{R_{i}}$ at the receiving antennas at each of the four receiving antennas due to $\overrightarrow{W_{3}}$ when using no polarization diversity, as opposed to choice of different polarizations.

\begin{tabular}{|c|c|c|c|c|}
\hline & $\left|I^{A_{3}}\right|$ & $\left|I^{A_{4}}\right|$ & $\left|I^{A_{5}}\right|$ & $\left|I^{A_{6}}\right|$ \\
\hline $\begin{array}{c}\text { No } \\
\text { polariza } \\
\text { tion }\end{array}$ & 0.5814 & 0.2920 & 0.1533 & 0.3671 \\
\hline $\begin{array}{c}\mathrm{R}-\mathrm{H} \\
\text { polariza } \\
\text { tion }\end{array}$ & 1.0069 & 0.2463 & 0.0031 & 0.5987 \\
\hline $\begin{array}{c}\mathrm{L}-\mathrm{H} \\
\text { polariza } \\
\text { tion }\end{array}$ & 0.7241 & 0.1292 & 0.1216 & 0.4110 \\
\hline
\end{tabular}

\section{Conclusion}

A new method is presented for directing the signal to a particular receiving antenna by choosing the appropriate excitations on the transmitting antennas, thereby resulting in adaptivity on transmit. Polarization properties are also exploited. In this way, transmitted signals can be directed to a pre-selected receiver using a finite bandwidth in the presence of coherent multipath and near-field scatterers using the principle of reciprocity. Several numerical results using an electromagnetic simulation tool WIPL-D have been presented to illustrate the applicability of this novel approach based on the principles of reciprocity and superposition while simultaneously utilizing the polarization properties.

\section{References}

[1] G. B. Giannakis, Y. Hua, P. Stoica and L. Tong, Signal Processing Advances in Wireless \& Mobile Communications, Vol.1, Prentice Hall PTR, 2000.

[2] L. Setian, Antennas with Wireless Applications, Prentice Hall PTR , 1998.

[3] W. C. Jakes, Microwave mobile communications, John Wiley and Sons, 1974.

[4] S. P. Morgan, "Interaction of Adaptive Antenna Arrays in an Arbitrary Environment," Bell System Tech. J. 44, Jan. 1965.
[5] Y. S. Yeh, "An Analysis of Adaptive Retransmission Arrays in a Fading Environment," Bell System Tech. J. 44, Oct. 1970.

[6] S. M. Alamouti, "A Simple Transmit Diversity Technique for Wireless Communications", IEEE journal Select Areas In Communications, Vol. 16, No. 8, Oct. 1998.

[7] H.Lee, M. Shin and C.Lee, "An Eigen-based MIMO Multiuser Scheduler with Partial Feedbak Information", IEEE Communications Letters, Vol.9, No.4 Apr. 2005

[8] H. Sampath, P. Stoica, and A. Paulraj, "Generalized Linear Precoder and Decoder Design for MIMO Channels Using the Weighted MMSE Criterion," IEEE Trans. on Communications, Vol. 49, No.12, Dec. 2001.

[9] G. Lebrun, J. Gao, and M. Faulkner, "MIMO Transmission Over a Time Varying Channel Using SVD," IEEE Trans. on Wireless Communications, Vol. 4, No.2, Mar.2005.

[10] T. Dahl, N. Christophersen, and D.Gesbert, "Blind MIMO Eigen mode Transmission Based on the Algebraic Power Method, "IEEE Trans. on Signal Processing, Vol.52, No.9, Sept. 2004.

[11] S. Choi and D. Yun, "Design of Adaptive Antenna Array for Tracking the Source of Maximum Power and Its Applications to CDMA Mobile Communications," IEEE Trans. on Antennas and Propagation, Vol.45, No.9, Sept. 1997.

[12] S. Choi, D. Shim and T. K. Sarkar, "A Comparison of Tracking-Beam Arrays and Switching - Beam Arrays Operating in a CDMA Mobile Communication Channel," IEEE Antennas and Propagation Magazine, Vol.41, No.6 pp.10-22, Dec. 1999.

[13] R. C. Qui and I.T.Lu, "Multipath Resolving with Frequency Dependence for Wide Band Wireless Channel Modeling," IEEE Trans. On Vehicular Technology, Vol.48, 
No.1, Jan. 1999.

[14] G. D. Durgin and T. S. Rappaport, "Theory of Multipath Shape Factors for Small-scale Fading Wireless Channels," IEEE Trans. On Antennas and Propagation, Vol.48, No.5, May 2000.

[15] T. K. Sarkar, M. Wicks, M. Salazar Palma and R. Bonneau, Smart Antennas, John Wiley and Sons, 2003.

[16] R. F. Harrington, Time - Harmonic Electromagnetic Fields, Mc Graw - Hill, 1961.

[17] B. M. Kolundzija, J. S. Ognjanovic and T.K.Sarkar,WIPL-D,Electromagnetic Modeling of Composite Metallic and Dielectric Structures, Software and User's Manual, Artech House, 2004.

황 승 현 (Seunghyeon Hwang)

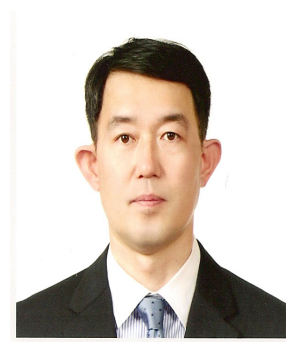

1991년 3월 육군사관학교 전자 공학과 졸업 1996년 5월 미.시라큐스대 전 자공학과 석사 2006년 5월 미.시라큐스대 전 자공학과 박사

2006년 2월 현재 방위사업청

사업계획담당

<관심분야> 전자공학, 방탐, 신호처리, 전파공학

\section{고 진 환 (Jinhwan Koh)}

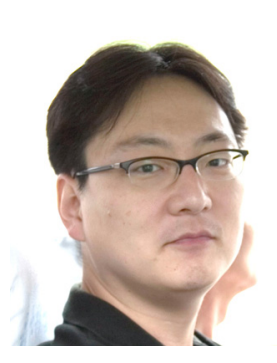

1991년 2월 인하대학교 전자 공학과 학사 1999년 12월 시라큐스대학 전 기공학과 박사 2003년 3월 현재 경상대학교 전자공학과 교수

자파측정, 신호처리 


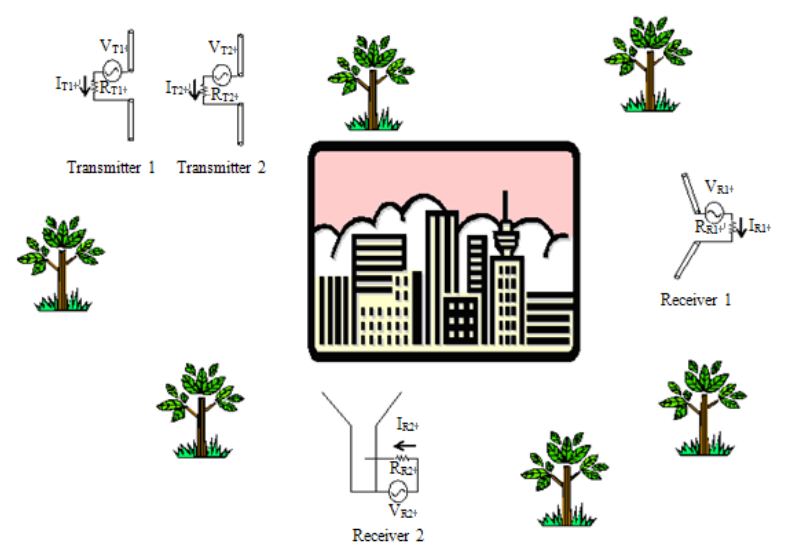

Fig. 1. A multiple-user transmit/receive scenario.

$\Psi_{\mathrm{A}_{3}} \emptyset_{\mathrm{A}_{4}} \Psi_{\mathrm{A}_{5}} \emptyset_{\mathrm{A}_{6}}$ Receiver
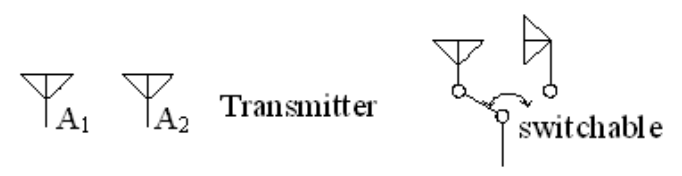

Co-located base station

Fig. 2. Configurations for multiple-users using linear polarizations.

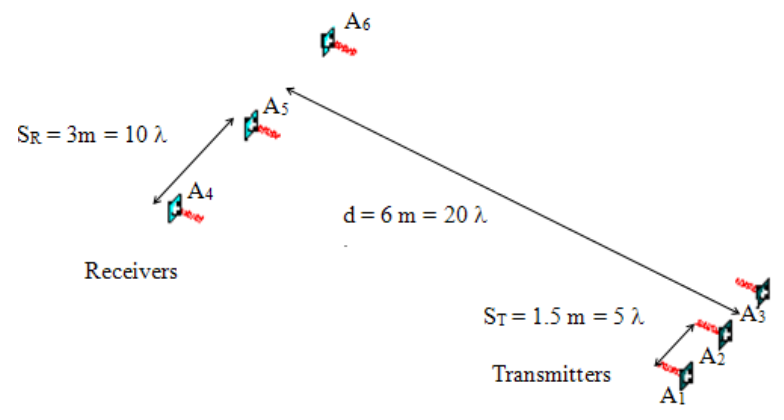

Fig. 3. A six helical antenna transmit/receive system.

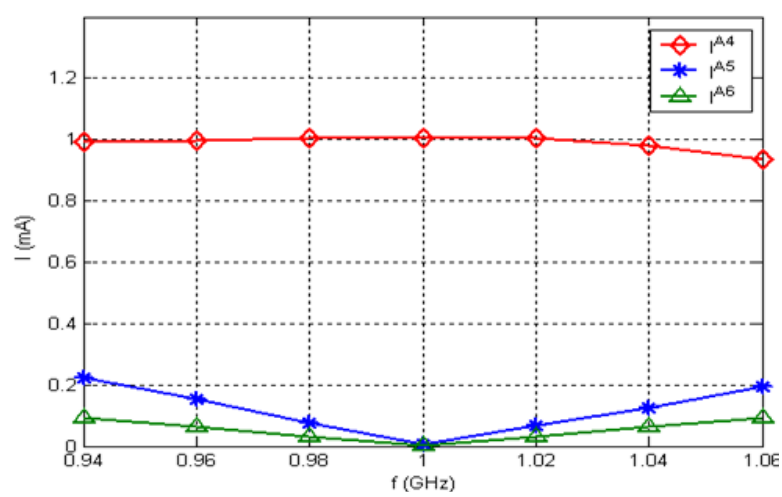

Fig. 4. Magnitude of the measured currents at the three receivers with $\overrightarrow{W_{4}}$

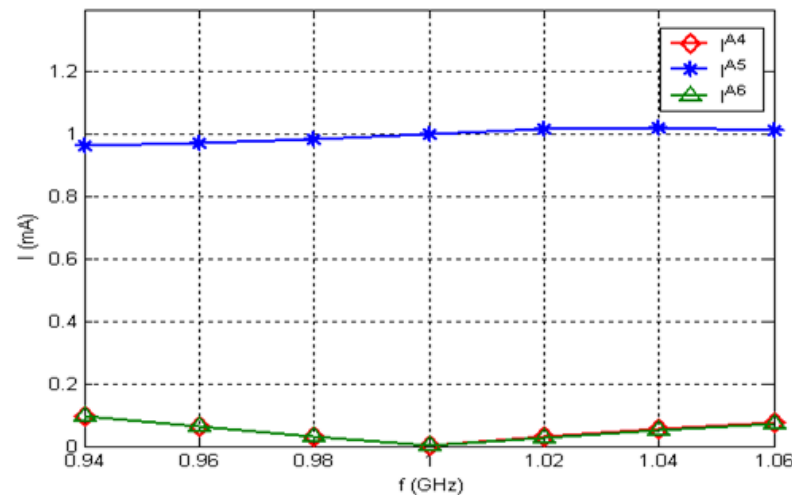

Fig. 5. Magnitude of the measured currents at the three receivers with $\overrightarrow{W_{5}}$

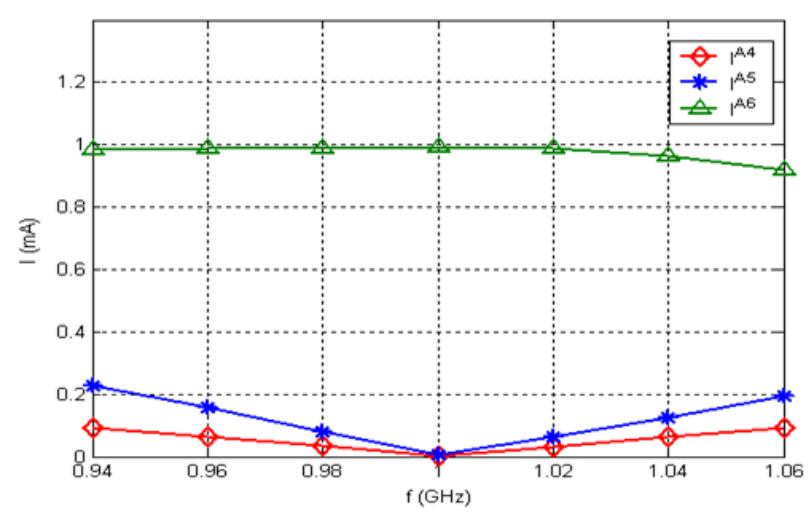

Fig. 6. Magnitude of the measured currents at the three receivers with $\vec{W}_{6}$ 


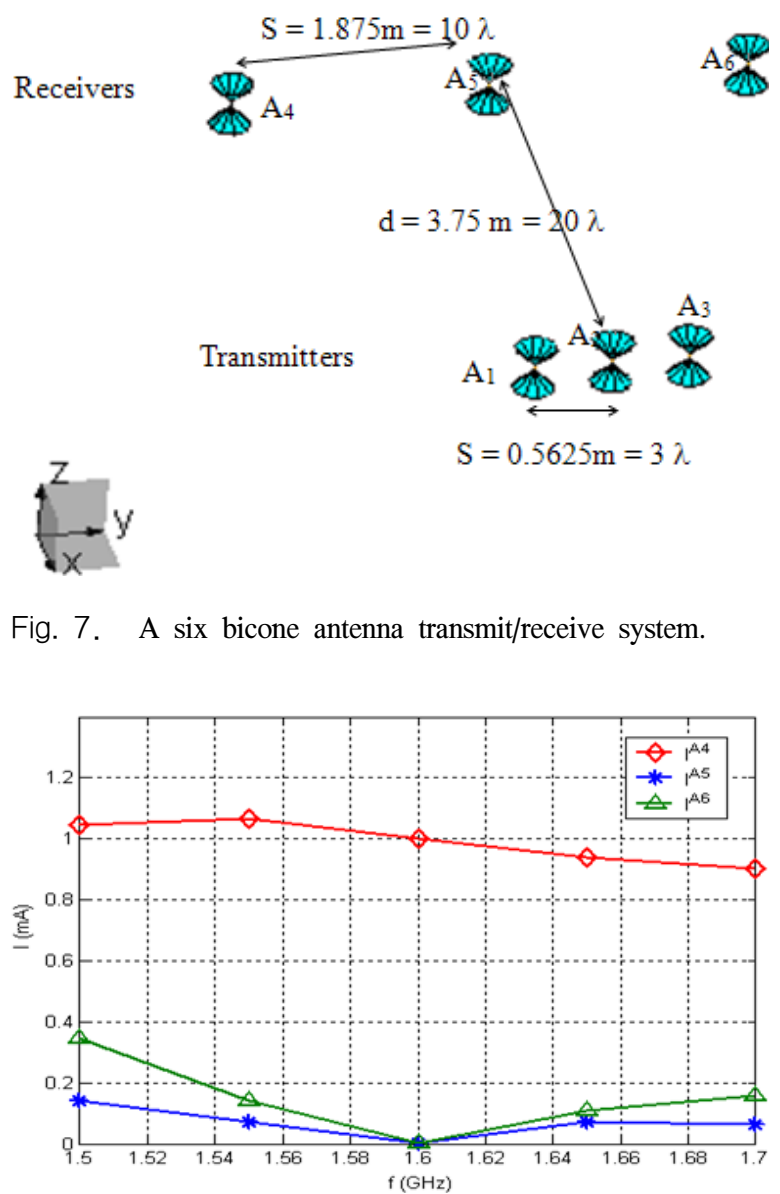

Fig. 8. Magnitude of the measured currents at the three receivers with $\overrightarrow{W_{4}}$

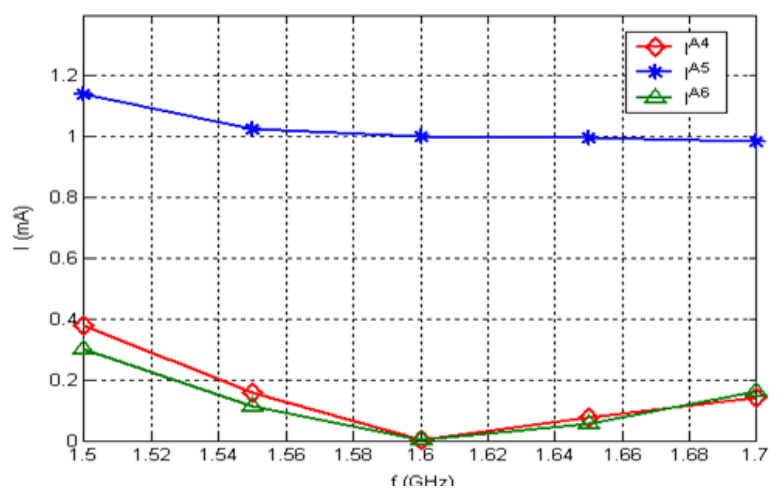

Fig. 9. Magnitude of the measured currents at the three receivers with $\overrightarrow{W_{5}}$

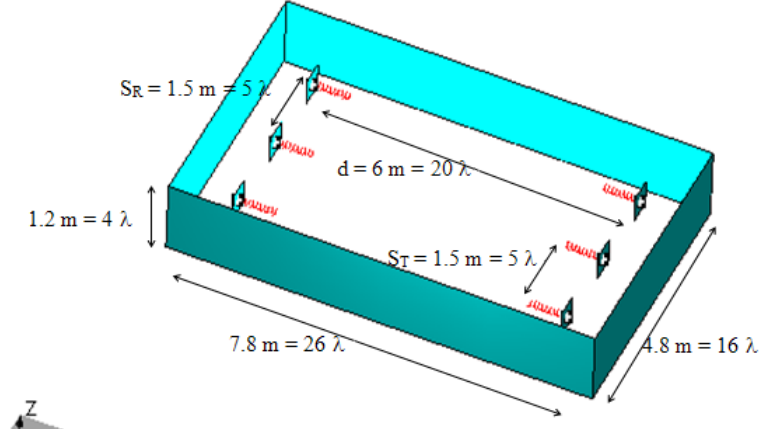

Fig. 10. A six helical antenna transmit/receive system inside of the cylinder.

$$
\begin{gathered}
\text { Receivers }{ }_{2-H}^{\mathrm{A}_{6}} \\
\mathrm{~L}-\mathrm{H} \mathrm{A}^{\mathrm{A}_{4}}
\end{gathered}
$$

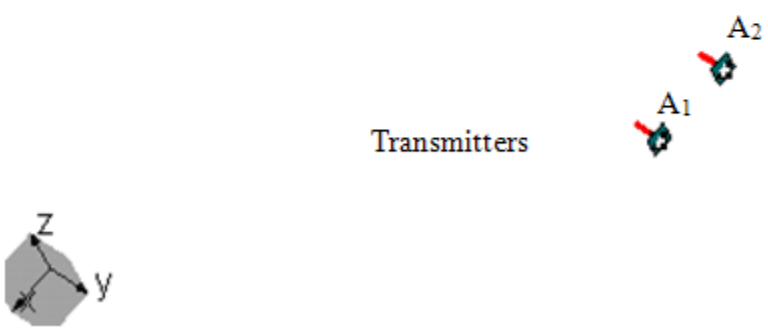

Fig. 11. A six helical antenna transmit/receive system in an open area.

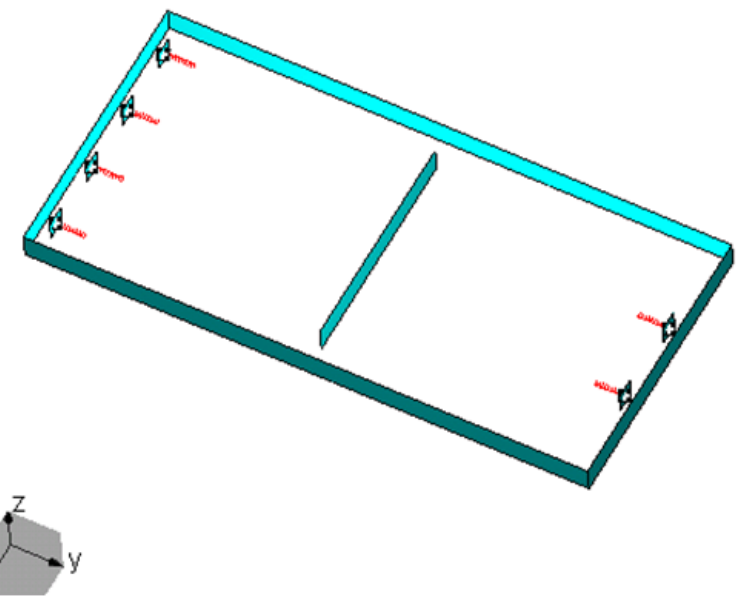

Fig. 12. A six helical antenna transmit/receive system inside of the cylinder with a wall. 